\title{
ПЕРЕДУМОВИ ТА РОЗРАХУНОК ДОВЖИН ПРОЛЬОТІВ ДЛЯ КОМПЕНСОВАНОЇ ПІДВІСКИ
}

\author{
Ю.С. Парфьонов, канд. техн. наук Н.В. Бєлікова
}

\section{ПРЕДПОСЫЛКИ И РАСЧЕТ ДЛИН ПРОЛЕТОВ ДЛЯ КОМПЕНСИРОВАННОЙ ПОДВЕСКИ}

\author{
Ю.С. Парфенов, канд. техн. наук Н.В. Беликова
}

\section{PREREQUISITES AND CALCULATION LENGTHS SPANS COMPENSATED FOR SUSPENSION}

\author{
J.S. Parfenov, cand. of techn. sciences N.V. Belikova
}

Довжина прольоту у великій мірі визначає як будівельну вартість контактної мережі, так $і$ надійність ї̈ роботи в умовах експлуатації. Чим більще довжина прольоту, тим дешевще контактна мережа, оскільки зменшується необхідне число опор $i$ різних підтримуючих пристроїв. Деяке збільшення несучої здатності опор та їх висоти при зростанні довжини прольоту, пов'язане із збільшенням стріли провисання несучого троса та конструктивної висоти ланцюгової підвіски, викликає збільшення вартості контактної мережі, але воно менше економії, що досягається при зменшенні числа опор. Тому з економічної точки зору завжди вигідно мати великі прольоти.

Ключові слова: контактна мережа, струмоприймач, стріла провисання проводу.

Длина пролета в большой степени определяет как строительную стоимость контактной сети, так и надежность ее работь в условиях эксплуатации. Чем больше длина пролета, тем дешевле контактная сеть, поскольку уменьшается необходимое число опор и различных поддержсивающих устройств. Увеличение несущей способности опор и их высоты при увеличении длины пролета связано с увеличением стрель провеса несущего троса и конструктивной высоты цепной подвески и влечет за собой увеличение стоимости контактной сети, но оно меньше экономии, которая достигается при уменьшении числа опор. Поэтому с экономической точки зрения всегда выгодно иметь большие пролетьл.

Ключевые слова: контактная сеть, токоприемник, стрела провеса провода.

Span length largely determines how the building cost of a contact network and the reliability of its operation in conditions. The longer the flight, the cheaper the network by reducing the required number of supports and different devices that support it. Some increase of bearing ability of the pillars and their height with the growth of the length of the span is connected with the increasing of the boom of the dip suspension cable and height of the catenary, causes the increase of the value of a contact network, but it is less the savings that are achieved in reducing the number of supports. Therefore, from an economic perspective it is always beneficial to have a large spans.

Keywords: Contact Network, trolley, wire sag.

Довжина прольоту у великій мірі визначає як будівельну вартість контактної мережі, так і надійність їі роботи в умовах експлуатації. Чим більше довжина прольоту, тим дешевше контактна мережа, оскільки зменшується необхідне число 
опор i різних підтримуючих пристроїв. Деяке збільшення несучої здатності опор та їх висоти при зростанні довжини прольоту, пов'язане із збільшенням стріли провисання несучого троса та конструктивної висоти ланцюгової підвіски, викликає збільшення вартості контактної мережі, але воно менше економії, що досягається при зменшенні числа опор. Тому з економічної точки зору завжди вигідно мати великі прольоти.

Однак при збільшенні довжин прольотів погіршуються умови струмознімання, оскільки посилюється нерівномірність еластичності контактної підвіски вздовж прольоту, збільшуються стріли провисання всіх проводів. Стріла провисання тим більше, чим більше навантаження на провід, і тим менше, чим сильніше натягнутий провід. Від довжини прольоту стріла провисання проводу знаходиться у квадратичній залежності: наприклад, при зменшенні прольоту в 2 рази стріла провисання зменшується в 4 рази.

Якщо не вжити спеціальних заходів для підтримки натягу проводу на певному рівні, його натяг і стріла провисання будуть змінюватися при коливаннях температури i навантаження. При збільшенні температури довжина проводу збільшиться, а значить, i його стріла провисання, і знижується натяг. При зниженні температури довжина проводу зменшується, що викликає зменшення стріли провисання і збільшення натягу.

Навантаження від власної ваги контактної підвіски g, daн/м, визначають підсумовуванням завантажень окремих проводів, з яких складається підвіска, струн і затискачів за формулою:

$$
\mathrm{g}=\mathrm{g}_{T}+n_{K} *\left(\mathrm{~g}_{K}+\mathrm{g}_{C}\right)
$$

де $\mathrm{g}_{T}$ - навантаження від ваги 1 м несучого троса, $\mathrm{g}_{T}=1,058 \mathrm{daH} / \mathrm{M}$;

$\mathrm{g}_{K}-$ навантаження від ваги 1 м контактного проводу, $\mathrm{g}_{K}=0,89 \mathrm{daH} / \mathrm{m}$; $\mathrm{g}_{c}$ - навантаження від ваги ресорного троса, струн і затискачів, dан/м, при $n_{K}=1$, $\mathrm{g}_{C}=0,1 \mathrm{daH} / \mathrm{M}$.

$\mathrm{g}=1,058+1 *(0,89+0,1)=2,048 \mathrm{daH} / \mathrm{M}$.

Навантаження від ваги ожеледі, $\mathrm{g}_{\mathrm{K \Gamma}}$, $\mathrm{daH} / \mathrm{m}$, визначається за формулою:

$$
\mathrm{g}_{\mathrm{K} \Gamma}=2,77 * \mathrm{~B}_{\mathrm{K}} *\left(d_{\mathrm{CP}}+\mathrm{B}_{\mathrm{K}}\right) \text {, }
$$

де $d_{\mathrm{CP}}$ - середній діаметр контактного проводу, мм.

$$
d_{\mathrm{CP}}=\frac{\mathrm{H}+\mathrm{A}}{2}
$$

де $\mathrm{H}$ - висота контактного проводу, $\mathrm{H}=11,8 \mathrm{~mm}$;

А - ширина контактного проводу, $\mathrm{A}=12,38 \mathrm{мм}$;

$\mathrm{B}_{\mathrm{K}}$ - розрахункова товщина стінки ожеледі на контактному проводі, мм.

$$
\mathrm{B}_{\mathrm{K}}=0,5 * b_{T},
$$

де $b_{T}-$ товщина стінки ожеледі на несучому тросі, мм.

$$
b_{T}=b_{\mathrm{H}} * \mathrm{~K}_{\Gamma} \text {, }
$$

де $b_{\mathrm{H}}$ - нормативна товщина стінки ожеледі по шару намерзання відповідно до району, $b_{\mathrm{H}}=20$ мм;

$\mathrm{K}_{\Gamma}$ - коефіцієнт, який ураховує діаметр проводу й висоту підвіки.

$$
\mathrm{K}_{\Gamma}=1-\frac{(1-0,9) *(d-10)}{20-10},
$$

де $\mathrm{d}$ - діаметр несучого троса, $\mathrm{d}=14$ мм.

$$
\mathrm{K}_{\Gamma}=1-\frac{(1-0,9) *(14-10)}{20-10}=0,96 .
$$

Визначаємо середній діаметр контактного проводу:

$$
d_{\mathrm{cp}}=\frac{11_{s} 8+12,8}{2}=12,3 \mathrm{MM}
$$


Товщина стінки ожеледі на несучому тросі: $b_{T}=20 * 0,96=19,2$ мм.

Товщина стінки ожеледі на контактному проводі: $\mathrm{B}_{\mathrm{K}}=0,5^{*} 19,2=9,6$ мм.

Навантаження від ваги ожеледі на контактному проводі:

$\mathrm{g}_{\mathrm{K \Gamma}}=2,77 * 9,6 *(12,3+9,6) * 10^{-3}=0,582 \mathrm{daH} / \mathrm{M}$.

Навантаження від ваги ожеледі на

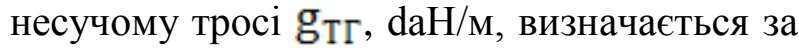
формулою:

$\mathrm{g}_{\mathrm{T \Gamma}}=2,22 * b_{T} *\left(d+b_{T}\right) * 10^{-3}=$ $=2,22 * 19,2 *(14+19,2) * 10^{-3}=1,415 \mathrm{daH} / \mathrm{M}$.

Розподілене лінійне навантаження від ваги ожеледі на струнах i затискачах $\mathrm{gcr}_{\mathrm{c}}$ daH/м, визначається за формулою:

$$
\mathrm{g}_{\mathrm{Cr}}=0,489 * b_{T} *\left(1,15 * b_{T}+d_{\mathrm{C}}\right) * 10^{-3},
$$

де $d_{\mathrm{C}}$ - діаметр струн, $d_{\mathrm{C}}=4 \mathrm{Mм}$,

$$
\mathrm{g}_{\mathrm{Cr}}=0,489 * 19,2 *\left(1,15^{*} 19,2+4\right) * 10^{-3}=
$$$$
=0,244 \mathrm{daH} / \mathrm{M} \text {. }
$$

Результуюче навантаження від ваги ожеледі на проводах контактної мережі $\mathrm{g}_{\Gamma}, \mathrm{daH} / \mathrm{m}$, визначається за формулою:

$$
\mathrm{g}_{\Gamma}=\mathrm{g}_{\mathrm{T} \Gamma}+n_{\mathrm{K}} *\left(\mathrm{~g}_{\mathrm{K \Gamma}}+\mathrm{g}_{\mathrm{C \Gamma}}\right)=
$$

$=1,415+1 *(0,582+0,244)=2,241 \mathrm{daH} / \mathrm{M}$.

Навантаження під дією вітру.

Горизонтальне вітрове навантаження на провід контактної мережі $P_{T V}$ і $P_{K V}$, $\mathrm{daH} / \mathrm{m}$, визначається за формулами:

$$
\begin{aligned}
& P_{T V}=B_{V} * C_{X} * \mathrm{~d} * 10^{-4}, \\
& P_{K V}=B_{V} * C_{X} * \mathrm{H}^{*} 10^{-4},
\end{aligned}
$$

де $B_{V}$ - нормативне розподілене поверхневе навантаження, $B_{V}=630$ Па (відповідає IV району по вітру);

$\mathrm{d}, \mathrm{H}$ - діаметр троса й висота контактного проводу;

$C_{X}$ - аеродинамічний коефіцієнт лобового опору вітру, $C_{X}=1,25$.

$$
\begin{aligned}
& P_{T V}=630 * 1,25 * 14 * 10^{-4}=1,102 \mathrm{daH} / \mathrm{M}, \\
& P_{K V}=630 * 1,25 * 11,8 * 10^{-4}=0,929 \mathrm{daH} / \mathrm{M} .
\end{aligned}
$$

Горизонтальне вітрове навантаження на проводи контактної мережі, вкриті ожеледицею $P_{\mathrm{T \Gamma}}$ i $P_{\mathrm{K \Gamma}}$, daH/м, визначаються за формулами:

$$
\begin{aligned}
& P_{\mathrm{T \Gamma}}=B_{\Gamma} * C_{X} *\left(\mathrm{~d}+2 b_{T}^{T}\right) * 10^{-4}, \\
& P_{\mathrm{K \Gamma}}=B_{\Gamma} * C_{X} *\left(\mathrm{H}+b_{\mathrm{K}}^{T}\right) * 10^{-4},
\end{aligned}
$$

де $B_{\Gamma}$ - розподілене поверхневе навантаження на проводах, покритих ожеледдю, $B_{\Gamma}=200$ Па (відповідає IV району по ожеледі).

При визначенні статичної складової вітрового навантаження на несучий трос із ожеледдю необхідно врахувати значення навантаження при ожеледі, яке можна розв'язати зменшуючи стінку льоду на проводі $b_{T}^{T}$ і $b_{\mathrm{K}}^{T}$ :

$$
b_{T}^{I}=-0,5 \mathrm{~d}+\sqrt{0,25 d^{2}+0,8 B_{K} *\left(d+B_{K}\right)}=
$$

$=-0,5 * 14+\sqrt{0,25 * 14^{2}+0,8 * 9,6(14+9,6)}=$ $=8,17 \mathrm{MM}$,

$$
b_{\mathrm{K}}^{T}=0,5 * b_{T}^{T}=0,5 * 8,17=4,08 \mathrm{MM} .
$$

Визначаємо горизонтальне вітрове навантаження на проводи контактної мережі:

$P_{\mathrm{Tr}}=200 * 1,25 *(14+2 * 18) * 10^{-4}=0,758 \mathrm{daH} / \mathrm{M}$, $P_{\mathrm{K} \Gamma}=200 * 1,25 *(11,8+4,08) * 10^{-4}=0,397 \mathrm{daH} / \mathrm{M}$ $\mathrm{g}_{V}$ :

Результуюче навантаження при вітрі $\mathrm{g}_{V}=\sqrt{\mathrm{g}^{2}+P_{T V}^{2}}=\sqrt{2,048^{2}+1,102^{2}}=2,325 \mathrm{daH} / \mathrm{M}$.

Результуюче навантаження на несучий трос при спільному вітрі 3 ожеледдю, gГ,

$\mathrm{g}_{\Gamma}=\sqrt{\left(\mathrm{g}+P_{T V}\right)^{2}+P_{\mathrm{T \Gamma}}^{2}}=$ $=\sqrt{(2,048+1,102)^{2}+0,758^{2}}=4,355 \mathrm{daH} / \mathrm{M}$. 
Визначення

розрахункового режиму:

$$
\begin{gathered}
P_{K V}=C_{X} * \frac{\left(K_{B} * V_{H}\right)^{2}}{16} * \mathrm{H} * 10^{-3}, \\
P C_{X} * \frac{\left(K_{B} * V_{\Gamma}\right)^{2}}{16} *\left(\mathrm{H}+2 * B_{\mathrm{K}}\right) * 10^{-3},
\end{gathered}
$$

де $\mathrm{K}_{\mathrm{B}}$ - коефіцієнт швидкості вітру на перегоні, пряма ділянка $\mathrm{K}_{\mathrm{B}}=1$, крива - $\mathrm{K}_{\mathrm{B}}=1,15$;

$V_{H}$ - нормативна швидкість вітру, $V_{H}=32 \mathrm{M} / 3$;

$V_{\Gamma}$ - нормативна швидкість вітру при ожеледі, $V_{\Gamma}=18 \mathrm{~m} / \mathrm{c}$.

Визначення розрахункового режиму на прямій ділянці:

$P_{K V}=1,25 * \frac{(1 * 32)^{2}}{16} * 11,8 * 10^{-3}=0,944 \mathrm{daH} / \mathrm{M}$,

$P_{\mathrm{K \Gamma}}=1,25 * \frac{(1 * 18)^{2}}{16} *(11,8+2 * 9,6) * 10^{-3}=$

$=0,785 \mathrm{daH} / \mathrm{M}$,

$P_{K V}>P_{\mathrm{K \Gamma}} ;(0,944>0,785)$ daH/M.

Ухвалюємо режим максимального вітру, тому що $P_{K V}>P_{\mathrm{K \Gamma}}$.

Визначення розрахункового режиму в кривій ділянці колії:

$P_{K V}=1,25 * \frac{(1,15 * 32)^{2}}{16} * 11,8 * 10^{-3}=$

$=1,248 \mathrm{daH} / \mathrm{M}$,

$P_{\mathrm{KT}}=1,25 * \frac{(1,15 * 18)^{2}}{16} *(11,8+2 * 9,6) * 10^{-3}=$

$=1,037 \mathrm{daH} / \mathrm{M}$,

$P_{K V}>P_{\mathrm{K \Gamma}} ;(1,248>1,037) \mathrm{daH} / \mathrm{M}$.

Ухвалюємо режим максимального вітру, тому що $P_{K V}>P_{\mathrm{K \Gamma}}$.

Максимально припустима довжина прольоту $L_{\max }$, м, визначається за формулою:

на прямій ділянці
$L_{\max }=2 * \sqrt{\frac{\mathrm{K}}{\mathrm{P}_{\mathrm{R}} * \mathrm{~K}_{1}-\mathrm{P}_{\mathrm{E}}}\left[b_{\text {доп }}-\gamma_{\mathrm{K}} \sqrt{\left(b_{\text {доп }}-\gamma_{\mathrm{K}}\right)^{2}-a^{2}}\right]}$

на кривій ділянці

$L_{\max }=2 * \sqrt{\frac{2 \mathrm{~K}}{\mathrm{P}_{\mathrm{K}} * \mathrm{~K}_{1}-\mathrm{P}_{\mathrm{E}}+\frac{\mathrm{K}}{R}} *\left(b_{\text {доп }}-\gamma_{\mathrm{K}}+a\right]}$,

Ці формули можна спростити введенням коефіцієнтів:

$\mathrm{B}_{\text {пр }}=\left[b_{\text {доп }}-\gamma_{\text {к }} \sqrt{\left(b_{\text {доп }}-\gamma_{\mathrm{\kappa}}\right)^{2}-a^{2}}\right]$,

$\mathrm{B}_{\text {кр }}=\left(b_{\text {доп }}-\gamma_{\mathrm{K}}+a\right]$,

де $\mathrm{K}$ - номінальне навантаження контактних проводів, ДО=1000 daH/м;

$\mathrm{R}$ - радіус кривої, м;

$\mathrm{P}_{\mathrm{K}}$ - розрахункове навантаження на контактний провод, daH/M;

$\mathrm{P}_{\mathrm{E}}$ - питоме еквівалентне навантаження, яке враховує взаємодію несучого троса й контактного проводу при їхньому відхиленні під дією вітру, daH/м;

$\mathrm{B}_{\text {пр }}, \mathrm{B}_{\text {кр }}-$ коефіцієнти, що залежать від швидкості вітру, $\mathrm{B}_{\text {пр }}=0,866, \mathrm{~B}_{\text {кр }}=0,835$;

$\mathrm{K}_{1}$ - коефіцієнт, який ураховує динамічну складову вітрового навантаження.

Коефіцієнт, який ураховує динамічну складову вітрового навантаження $\mathrm{K}_{1}$, визначається за формулою:

$$
\mathrm{K}_{1}=\mathrm{K}_{2}+2 * \eta * \delta * \sigma,
$$

де $\eta \delta$ - коефіцієнти, які враховують пульсацію вітру;

$\sigma$ - коефіцієнт динамічності;

$\mathrm{K}_{2}$ - коефіцієнт, який ураховує групи деформації проводу при його відхиленні.

Коефіцієнт, який ураховує групи деформації проводу при його відхиленні $\mathrm{K}_{2}$, знаходимо за формулою:

$$
\mathrm{K}_{2}=\mathrm{K}_{3} * \mathrm{~K}_{4} * \mathrm{~K}_{5} \text {, }
$$


де $\mathrm{K}_{3}-$ коефіцієнт, який залежить від довжини прольоту;

$\mathrm{K}_{4}$ - коефіцієнт, який залежить від швидкості вітру;

$\mathrm{K}_{5}$ - коефіцієнт, який залежить від типу контактного проводу.

Визначаємо максимально-припустиму довжину прольоту на прямій ділянці колії $L_{\max }$, прийнявши $\mathrm{P}_{\mathrm{E}}=0, \mathrm{~K}_{1}=1$ :

$$
L_{\max }=2 \sqrt{\frac{1000 * 0,866}{0,944 * 1-0}}=60,5 \mathrm{M} .
$$

Визначаємо коефіцієнти $\mathrm{K}_{1}, \mathrm{~K}_{2}$ :

$\mathrm{K}_{2}=0,66 * 1,41 * 1,01=0,939$;

$\mathrm{K}_{1}=0,939+2 * 0,6 * 0,92=1,13$.

Визначаємо максимально-припустиму довжину прольоту на прямій ділянці колії $L_{\max }$, прийнявши $\mathrm{P}_{\mathrm{E}}=0, \mathrm{~K}_{1}=1,15$ :

$$
L_{\max }=2 \sqrt{\frac{1000 * 0,866}{0,941 * 1,13-0}}=56,6 \mathrm{M} .
$$

$$
\mathrm{P}_{\mathrm{E}}=\frac{\mathrm{P}_{\mathrm{K}} * \mathrm{~T}-P_{T} * \mathrm{~K}-\frac{8 * K * T}{L^{2}} *\left(\frac{h_{i * P_{T}}}{\mathrm{~g}_{\mathrm{T}}}+\gamma_{T}-\gamma_{k}\right)}{T+K+\frac{10,6 * S_{C p} * K * T}{\mathrm{~g}_{k} * L^{2}}},
$$

де Т-T - натяг несучого троса в розрахунковому режимі, $\mathrm{T}=1600 \mathrm{daH} / \mathrm{M}$;
$P_{T}$ - вітрове навантаження на несучий трос у розрахунковому режимі, daн/м;

$\mathrm{L}$ - довжина прольоту, м;

$h_{i}$ - довжина гірлянди ізоляторів, $h_{i}=0,9 \mathrm{M}$;

$\gamma_{T}, \gamma_{k}-$ прогини опор на рівні несучого троса й контактного проводу, $\gamma_{T}=0,022 \mathrm{M}$, $\gamma_{k}=0,015 \mathrm{м}$;

$\mathrm{g}_{\mathrm{T}}$ - результуюче навантаження на несучий трос у розрахунковому режимі, $\mathrm{daH} / \mathrm{m}$;

$\mathrm{g}_{k}-$ вага контактної підвіски, daH/м;

$S_{c p}-$ середня довжина струни в середині прольоту, м.

Визначаємо середню довжину струни в середині прольоту $S_{c p}$, за формулою:

$$
\begin{aligned}
& S_{c p}=\mathrm{h}-0,115 \frac{\mathrm{g} * L^{2}}{T_{0}}= \\
& =1,8-0,115 \frac{2,048 * 56,6^{2}}{1600}=1,33 \mathrm{M},
\end{aligned}
$$

де h - конструктивна висота підвіски, $\mathrm{h}=1,8 \mathrm{~m}$;

$T_{0}$ - натяг несучого троса при бездротовому положенні контактного проводу, $T_{0}=\mathrm{T}=1600 \mathrm{daH}$.

Визначаємо еквівалентне навантаження $\mathrm{P}_{\mathrm{E}}$, для $L_{\max }=56,6$ м:

$$
\mathrm{P}_{\mathrm{E}}=\frac{0,944 * 1600-1,102 * 1000-\frac{8 * 1000 * 1600}{56,6^{2}} *\left(\frac{0,9 * 1,102}{2,325}+0,022-0,015\right)}{1600+1000+\frac{10,6 * 1,33 * 1000 * 1600}{0,89 * 56,6^{2}}}=-0,25 \mathrm{daH} / \mathrm{M},
$$

Визначаємо максимальну довжину прольоту $L_{\max }$, з урахуванням, що

$$
\begin{gathered}
\mathrm{P}_{\mathrm{E}}=-0,125 \mathrm{daH} / \mathrm{M}, \mathrm{K}_{1}=1,15: \\
L_{\max }=2 \sqrt{\frac{1000 * 0,866}{0,944 * 1,15-(-0,125)}}=53,5 \mathrm{M} .
\end{gathered}
$$

Згідно 3 нормативами у місцях, не захищених від вітру, довжини прольоту зменшують, відповідно ухвалюємо для проектування максимальну довжину прольоту $L_{\max }=52 \mathrm{M}$.

Визначаємо максимально-припустиму довжину прольоту в кривій ділянці колії 
$L_{\max }$, радіусом $\mathrm{R}=600$ м, прийнявши $\mathrm{P}_{\mathrm{E}}=0$, $\mathrm{K}_{1}=1$ :

$$
L_{\max }=2 \sqrt{\frac{2 * 1000 * 0,835}{1,248 * 1-0+\frac{1000}{600}}}=48 \mathrm{M} .
$$

Визначаємо коефіцієнти $\mathrm{K}_{1}, \mathrm{~K}_{2}$ :

$\mathrm{K}_{2}=0,68 * 1,41 * 1,01=0,968$;

$\mathrm{K}_{1}=0,968+2 * 0,65 * 0,2 * 0,92=1,2$.

Визначаємо максимальну довжину прольоту $L_{\max }$, з урахуванням, що $\mathrm{P}_{\mathrm{E}}=0, \mathrm{~K}_{1}=1,2$ :

$$
L_{\max }=2 \sqrt{\frac{2 * 1000 * 0,835}{1,248 * 1,2-0+\frac{1000}{600}}}=46 \mathrm{M} .
$$

Визначаємо середню довжину струни в середині прольоту $S_{c p}$ :

$$
S_{1,8-0,115} \frac{2,048 * 46^{2}}{1600}=1,49 \text { м. }
$$

Визначаємо еквівалентне навантаження $\mathrm{P}_{\mathrm{E}}$, для $L_{\max }=46 \mathrm{м}$ :

$$
\mathrm{P}_{\mathrm{E}}=\frac{1,248 * 1600-1,102 * 1000-\frac{8 * 1000 * 1600}{46^{2}} *\left(\frac{0,9 * 1,102}{2,325}+0,022-0,015\right)}{1600+1000+\frac{10,6 * 1,49 * 1000 * 1600}{0,89 * 46^{2}}}=-0,11 \mathrm{daH} / \mathrm{M}
$$

Визначаємо максимальну довжину прольоту $L_{\max }$, з урахуванням $\mathrm{P}_{\mathrm{E}}=-0,11 \mathrm{daH} / \mathrm{M}$, $\mathrm{K}_{1}=1,2$ :

$$
L_{\max }=2 \sqrt{\frac{2 * 1000 * 0,835}{1,248 * 1,2-(-0,11)+\frac{1000}{600}}}=45,2 \mathrm{M} .
$$

Згідно 3 нормативами приймаємо максимальну довжину прольоту

$$
L_{\max }=40 \text { м. }
$$

Стріла провисання проводу буде змінюватися і при змінах навантаження на нього. Наприклад, у разі утворення на проводі ожеледних відкладень навантаження збільшиться, і стріла провисання стане більше. Під тиском вітру навантаження, що діє на провід, також збільшується, і провід відхиляється убік від вертикального положення.

Довжину прольоту вибирають завжди якомога більшою, але так, щоб була забезпечена необхідна надійність контактної мережі в експлуатації. Для цього потрібно, щоб при обраній довжині прольоту зберігалися нормальні умови струмознімання, тобто натискання струмоприймача не мало різких коливань у різних частинах прольоту, вітрові відхилення контактного проводу не викликали сходу проводу полоза струмоприймача, дотримувалися встановлені межі зміни висоти контактного проводу від рівня головок рейок на всіх перегонах і станціях.

\section{Список використаних джерел}

1. Інструкція 3 улаштування та утримання колії залізниць України [Текст]. - К.: Транспорт України, 2006. - 336 с.

2. Технология, механизация и автоматизация путевых работ [Текст]/ Э.В. Воробьева, К.Н. Дьякова. - М.: Транспорт, 1996. - 375 с.

3. Лехно, И.Б. Путевое хозяйство [Текст] / И.Б. Лехно. - М.: Транспорт, 1981. - 232 с.

4. Організація робіт з реконструкції залізниць [Текст]/ В.М. Астахов, Н.В. Бєлікова, Л.П. Ватуля, В.Г. Мануйленко. - Харків: УкрДАЗТ, 2006. - 151 с. 
5. Железнодорожное строительство. Организация, планирование и управление [Текст] / под ред. Г.Н. Жинкина. - М.: Транспорт, 2001. - 576 с.

6. Вопросы планирования и организации строительства железных дорог [Текст] / под ред. Г.Н. Жинкина. - М.: Транспорт, 1989. - 248 с.

Рецензент д-р техн. наук, професор О.М. Даренський

Парфьонов Юрій Сергійович, слухач ІППК гр. МЗ-3С-Б11.

Бєлікова Наталія Віталіївна, канд. техн. наук, доцент кафедри колії та колійного господарства.

Parfenov J.S., cand. of techn. sciences Belikova N.V. 